\title{
Maria Mitchell
}

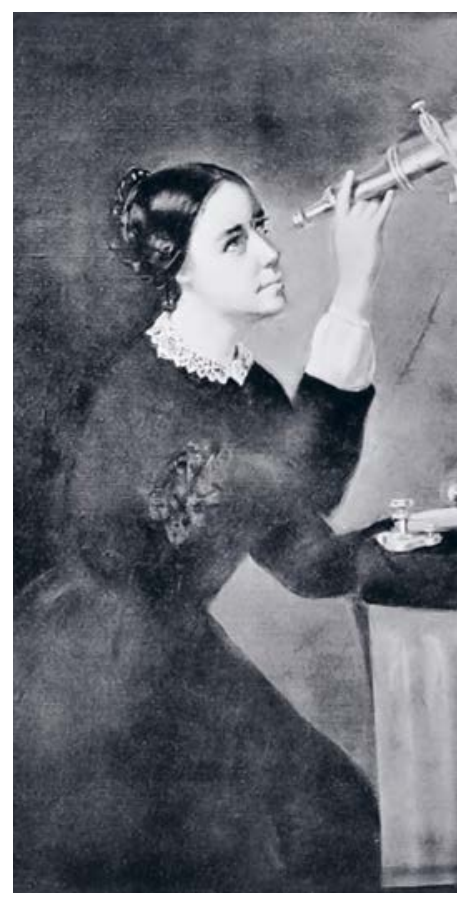

\author{
LuCie LEBOULLEUX \\ Univ. Grenoble Alpes, CNRS, IPAG, 38000 Grenoble, France \\ *lucie.leboulleux@univ-grenoble-alpes.fr
}

Maria Mitchell was a pioneer in many aspects: first observer of a comet with a telescope, she received the Gold Medal from the King of Denmark and became the first female astronomer and astronomy professor in the United States of America. But she also got involved in feminism, participating in the foundation of the Association for the Advancement of Women in 1873 as well as promoting the access to higher education for women and their inclusion in science.

\section{https://doi.org/10.1051/photon/202111028}

This is an Open Access article distributed under the terms of the Creative Commons Attribution License (http://creativecom mons.org/licenses/by/4.0), which permits unrestricted use, distribution, and reproduction in any medium, provided the original work is properly cited. Picture by H. Dassell - Sweeper in the Sky: The Life of Maria Mitchell, First Woman Astronomer in America by Helen Wright, 1914-1997, New York: The Macmillan Company, 1949 (public domain)

\section{First years}

Maria Mitchell was born on August $1^{\text {st }} 1818$ on the Nantucket Island in Massachusetts. At this time, women did not have many opportunities to access proper education, but her situation was uncommon: her parents, Lydia Coleman Mitchell, a library employee, and William Mitchell, a teacher and amateur astronomer, were educated and raised their 10 children according to the Quaker religion, valuing women education as much as men education. As a teenager, Maria Mitchell assisted her father both at school and during night observations $\leq$ : she quickly learnt to use a telescope and became passionate about astronomy. At 17 years old, she founded her own school where she applied non-conventional teaching methods and allowed African-American students despite of the ongoing segregation in public institutions. She then became librarian at the Nantucket Atheneum, which enabled her to study on her own and, almost every night, she climbed on the Pacific Bank rooftop, where her father was working, to observe the night sky with a telescope provided for them by the Coast Survey.

\section{Miss Mitchell's comet}

It was during one of these night observations that, on October $1^{\text {st }} 1847$, at 29 years old, she discovered the comet C/1847 T1 (named 1847 VI back then), a so-called telescopic comet since it is invisible to the naked eye and can only be detected with a telescope. With this finding, she became the third woman to discover a comet after Maria Margarethe Kirch (comet of 1702) and Caroline Herschel (8 comets from 1786 to 1797) and the first American person, among both men and women, first detecting one. Two days later, Father Francesco de Vico in Rome (Italy) observed the same comet. Since he published its coordinates before Maria Mitchell did, he temporarily received credit for this discovery, resulting in a short argument

\section{KEY DATES}

\begin{tabular}{lll}
\hline & I & $\mid$ \\
August $1^{\text {st }}$ 1818: & October $1^{\text {st }} \mathbf{1 8 4 7}$ & $1865:$ \\
Birth (Nantucket Island, & Discovery of the & Astronomer and \\
Massachusetts) & Miss Mitchell's Comet & professor at the Vassar \\
& & College (New York State)
\end{tabular}


between the two astronomers: indeed the question of the prior settlement was particularly crucial since the previous King of Denmark, Frederik VI, had promised a Gold medal to the first observer of a telescopic comet. Once the credit of her discovery established, the Gold medal was eventually awarded to Maria Mitchell by the king Christian VIII of Denmark and the comet was named after her: Miss Mitchell's comet [1]. Her career then took an unexpected turn with an immediate international recognition.

\section{The scientific Maria Mitchell}

After this discovery and her novel fame, Maria Mitchell was welcomed in several American institutions. In 1848, she was elected member of the American Academy of Arts and Sciences, becoming the first woman to join it. Female admissions were officially not allowed before 1943, a promotion that included, between others, Cecilia Payne-Gaposchkin (see Photoniques 100, 24-26 (2020)). In 1850, Maria Mitchell was also the first woman to enter into the American Association for the Advancement of Science and, in 1869, she joined in particular Mary Somerville and Elizabeth Cabot Agassiz at the American Philosophical Society.

In 1849, she accepted a position as a researcher and human computer at the US Nautical Almanac Office of the U.S. Coast Survey, becoming the first female professional astronomer in the USA. Her work consisted in studying the motion of the Venus planet and in arduously computing its position to guide navigators over seas. She worked eight years as a computer before travelling to and through Europe, where she visited numerous observatories such as the ones of Caroline and Sir John Herschel and of Mary Somerville. In 1865 and despite her inexistent degree, she was hired at the Vassar College, a young university for women only back then, and was even named director of the Vassar College Observatory. Once again, Maria Mitchell remained a pioneer since she became the first female professor in astronomy. Her teaching methods were as eccentric as in her younger years: she refused to give marks for evaluations and asked for reduced classes to provide personalized support for her students. She also allowed them to come to the university by night to observe with the telescope and organized missions away for astronomical events such as the total solar eclipse of 1869 , defying once again social protocols for women of the XIX ${ }^{\text {th }}$ century. Within her students, one can find Vera Rubin who would also become a famous astronomer and Elizabeth Williams Champney who would dedicate her novel In the Sky Garden (1877) to her. Some time after having begun to teach and despite her director responsibilities, she discovered that she and Alida Avery, her only female colleague, received wages lower than male professors: they both demanded higher wages, which they were granted with.

Maria Mitchell left the Vassar College in 1888 to retire to her sister to Lynn, in Massachusetts. She died there the following year from a brain disease, on June $28^{\text {th }} 1889$, and was buried at the Prospect Hill cemetery, on the Nantucket Island that witnessed her birth.

1873:

Co-foundation of the Association for the Advancement of Women
June 28 ${ }^{\text {th }}$ 1889:

Death

(Nantucket Island, Massachusetts)

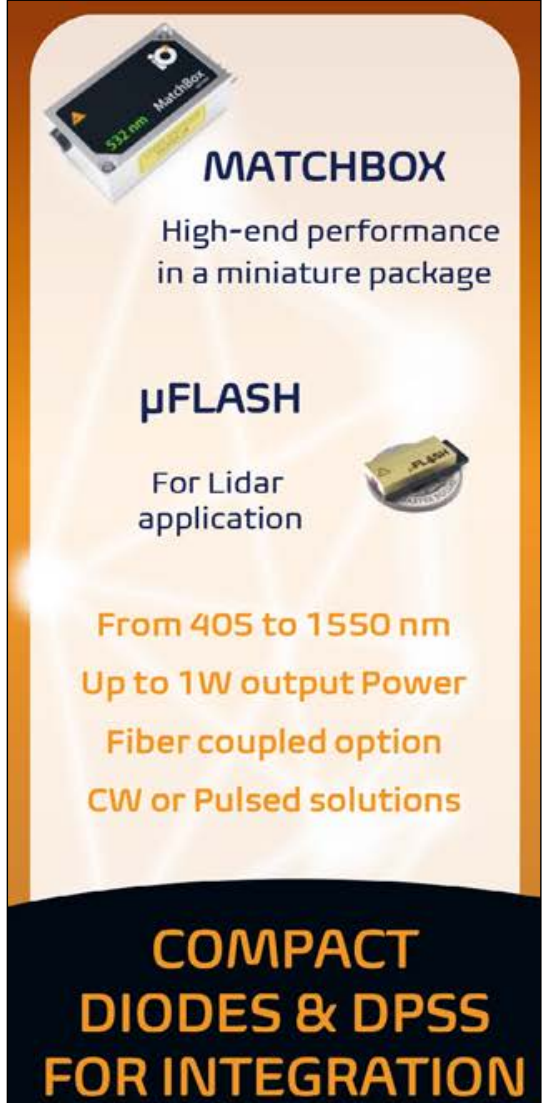

\section{LAMBDA BEAM}

DESIGNS

SOLUTIONS

Standard

WaveLock

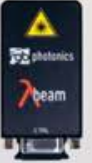

A

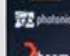

7 bean पive

Mini

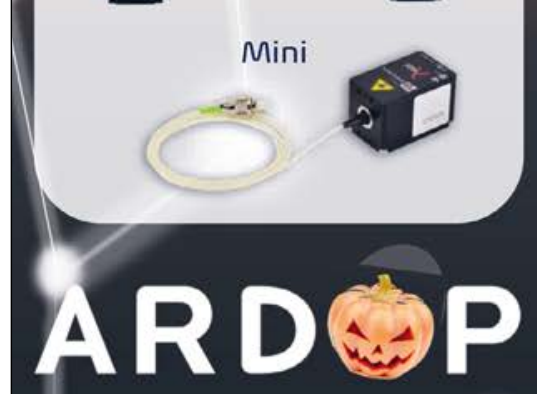

INDUSTRIE

\section{(+33) 05.40.25.05.36}

sales@ardop.com 


\section{The activist Maria Mitchell}

All along her lifetime, her various social and political convictions appeared in her activities and friendships: in particular, Maria Mitchell was a strong advocate against slavery, refusing to wear clothes made of cotton coming from Southern states and opening her school to African-American students. However, her feminist activism is still nowadays more recognized. In first place, she actively advocated for women right to vote and befriended several suffragettes such as Elizabeth Cady Stanton and Lucretia Mott. During her life, she also promoted the access of women to education and work, particularly concerning the scientific field. Allowing her students to observe by night at the observatory or during missions was already non-conventional for this epoch, but she even encouraged them to work, arguing they should remain independent and competitive at work.

In 1873, she co-founded the Association for the Advancement of Women (AAW) that aims to set up and promote the access and the advancement of women in all intellectual and cultural domains, mainly through education. If the AAW was directed, the first year, by Julia Ward Hore, Maria Mitchell became its president the following year and for two years. In 1876, at the fourth AAW congress hold in Philadelphia, she pronounced a speech that still remains known under the name The Need of Women in Science and that contains these words: "Does any one suppose that any woman in

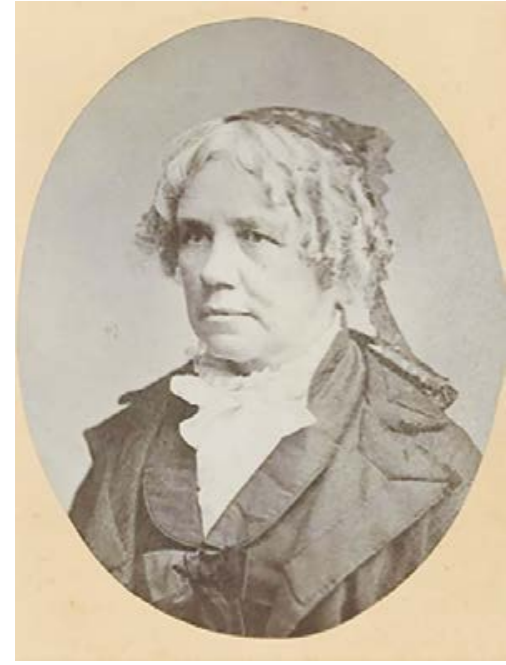

Figure 1. Maria Mitchell's portrait Nantucket Historical Association Research Library (public domain) fatigued"). In addition to tiredness, she mentioned measurement uncertainties that are also witnesses of the difficulty to observe at that time ("The color is peculiar","reddish").

Maria Mitchell was also curious and her researches spread between very diverse topics. The famous Miss Mitchell's comet [1] is nowadays known as a non-periodic comet with a hyperbolic orbit. In addition to Venus that she focused on as a human computer, she observed for a long time Jupiter satellites ([3], in which she refers to Io, Europe, Ganymede, and Callisto as numbers, as the norm back then required) and Saturn satellites ([4], where she explicitly names Tethys, Dione, Rhea, Encelade, and Titan). Maria Mitchell also focused on the Sun and suggested that solar patterns could be due to surface irregularities like holes instead of clouds. Eventually, she observed several double stars, thoroughly reporting her coordinates and characteristics [5].

\section{Honors}

From the discovery of the comet that holds her name, Maria Mitchell was internationally recognized. Her celebrity was meteoric and allowed her to join many associations both during her lifetime and posthumously. Thirteen years after her death, the Maria Mitchell association was founded to honor her memory, to perverse her works as well as to stimulate everyone's curiosity towards science. The association notably manages the Maria Mitchell's Observatory, on the Nantucket Island.

She entered into the Hall of Fame all the ages has had a fair chance to show what she could do in science? [...] until able women have given their lives to investigation, it is idle to discuss the question of their capacity for original work" [2].

\section{Scientific contributions}

Maria Mitchell's research is complex to perceive with certainty for the contemporary perspective. First, her archives are spread between a few scientific articles, outreach articles, notes, poems, her journal, and letters. In addition, if the XIX ${ }^{\text {th }}$ century witnessed the advent of spectroscopy and photography, two inventions mentioned in Maria Mitchell's writings (she used a chronograph during her observations), part of her measurements were made by eye, which she outlined in some of her articles ("I have taken great pains to notice the colors of the stars before my eye was for Great Americans in 1905, i.e., the first year a woman could integrate this gallery, and into the National Women's Hall of Fame in 1994.

In addition, many tributes are dedicated to her: a World War II Liberty Ship boat was named SS Maria Mitchell, a New York train is called Maria Mitchell Comet, and, probably more importantly to her view, one of the moon craters holds her name.

For the most curious readers, several books mention her or tell her story, such as Figuring from Maria Popova (2019), What Miss Mitchell Saw from Diana Sudkya and Hayley Barrett (2019) and Maria Mitchell and the Sexing of Science: An Astronomer among the American from Renée Bergland (2008). Last but not least, we have to cite her own biography, Maria Mitchell: Life Letters and Journals, posthumously published in 1896 by her sister, Phebe Mitchell [6]. 


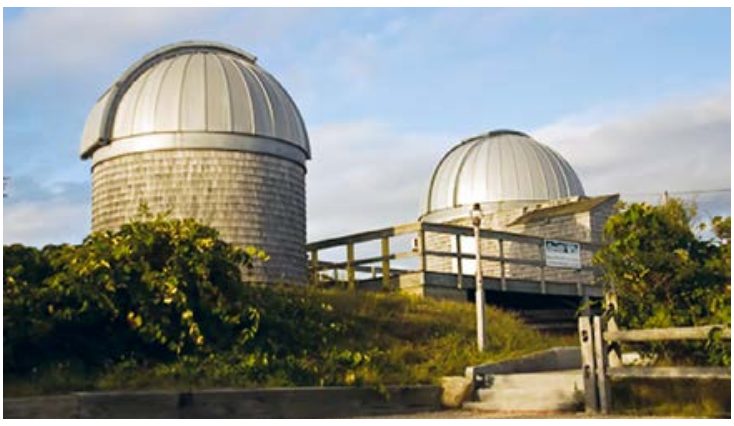

Fig. 2. Buildings of the Maria Mitchell Liones Observatory on Nantucket Island, Massachusetts - Bersageek.

CC BY-SA 3.0. Creative Commons Attribution-Share Alike 3.0 Unported license - https://creativecommons.org/licenses/ by-sa/3.0, via Wikimedia Commons.

\section{Nowadays}

Still today, Maria Mitchell would be a revolutionary. Her curiosity brought her to the observation of various objects and made her a pioneer in astronomy: first observer of a telescopic comet, first female professional astronomer in the USA, first female professor in astronomy, first woman elected in numerous science organizations... She also rapidly became a main figure of feminism, opening the path to women recognition in science and getting actively involved in access to education and science for women.

Her own words best summarize her impact on society and astronomy: "do not most persons, even of the intelligent classes, believe that above all other things a woman's first duty is to be useful in the kitchen and ornamental in the parlor? It belongs to women themselves to introduce a better order of things. [...] "Society" is certainly fashioned by women"[7].

\section{REFERENCES}

[1] M. Mitchell, Not. R. Astron. Soc. 8, 130 (1848)

[2] M. Mitchell, The Need of Women in Science, Fourth Congress of Association for the Advancement of Women, Philadelphia PA (1876)

\section{[3] M. Mitchell, Am. J. Sci. 6, 393 (1871)}

[4] M. Mitchell, Am. J. Sci. 102, 430 (1879)

[5] M. Mitchell, Am. J. Sci. 106, 38 (1863)

[6] M. Mitchell, Maria Mitchell: Life Letters and Journals (1896)

[7] M. Mitchell, The Higher Education of Woman, First Woman's Congress of the Association for the Advancement of Women, Union League Theater, New York City (1873)

[8] R. Holmes, Nature 558, 370-371 (2018)

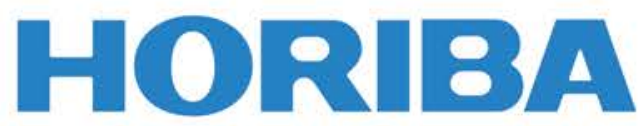

Scientific
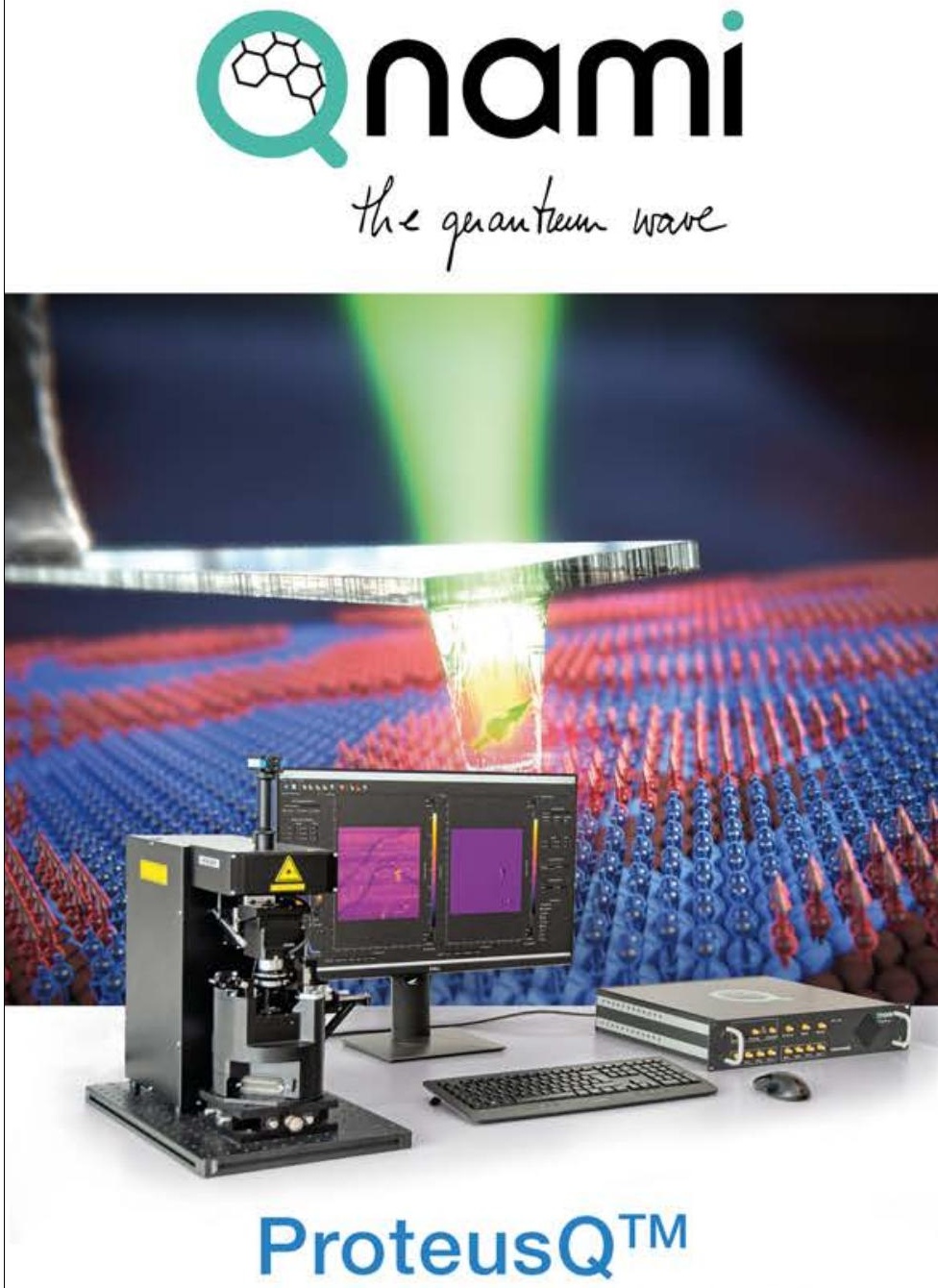

The first quantum microscope dedicated to magnetic materials analysis

\section{Specifications:}

- Enables mapping of a wide range of magnetic signals

- Scanning Nitrogen-Vacancy (NV) magnetometer

- Non-disruptive analysis

- Atomic precision

- Nanoscale resolution

- Intuitive and easy to use

- Upgradeable with standard SPM modules

\section{Applications :}

- Antiferromagnetic spintronics

- Ultra-thin ferro-magnets

- Multiferroic materials

- 2D materials

- Skyrmions, Magnons

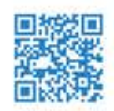

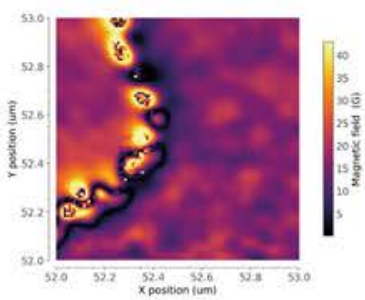

Magnetic field map of a synthetic antiferromagnet

\section{horiba.com/en_en/nv-magnetometry}

